\title{
Overweight and Obesity Status with Dental Caries among Children Aged 7-12 Years Old in Badung District, Bali 2018
}

\author{
Hariani Rafitha1, Putri Bungsu1 ${ }^{*}$, Ratna Djuwita1, Dwi Gayatri1, Fakhrana Ariani Ayub²
} 1Epidemiology Department, Faculty of Public Health, Universitas Indonesia, Depok, Indonesia, ${ }^{2}$ Prosthodontics
Department, Faculty of Dentistry, Universitas Indonesia, Jakarta, Indonesia

\begin{abstract}
Dental caries is an infectious disease that dental is characterized by the dental damage resulting from microorganism products in carbohydrate fermentation. Dental caries and obesity in children are multifactorial diseases associated with eating habits and certain lifestyle factors. This study aimed to assess the association between overweightness, obesity, and dental caries among children aged 7-12 years in Badung District, Bali Province in 2018. The total sample of 426 children and their mothers were recruited from all first to fifth elementary grade students in three schools selected by simple random sampling. The logistic regression analysis has demonstrated a significant association between obesity and dental caries (OR: 1.830; 95\% Cl: 1.230-2.722) and showed that after controlling for the confounding variables, obese children have a twice higher chance of experiencing dental caries than non-obese children. Therefore, strengthening the existing health education programs in schools, including those on healthy food or snack components, and improving the efficiency of physical activities for preventing obesity could be a short-term strategy to protect school children from childhood obesity and dental caries.
\end{abstract}

Keywords: Badung District, dental caries, elementary school dental health, obesity

\section{Introduction}

Caries is the most common infectious disease in childhood, affecting $60 \%$ - $90 \%$ of children worldwide. ${ }^{1}$ Children aged 6-11 years have experienced permanent dental caries with various proportions from $14 \%$ to $29 \%$ in $2011-2012 .{ }^{2}$ In addition, studies pointed out the varying prevalence of caries in children across the globe, with the values reaching $36 \%-85 \%$ in Asia, 38\% - 45\% in Africa, and $22 \%-61 \%$ in the Middle East. ${ }^{3}$ Cambodia and Indonesia reported that the excessive burden of dental caries in children has reached $90 \% .^{3}$ According to the 2007 National Basic Health Survey, the prevalence of child dental and oral problems in Indonesia was $23.4 \%$, which gradually increased to $25.9 \%$ in 2013.4 Moreover, the dental caries prevalence data in 2013 illustrated that $53.7 \%$ of Indonesian people had caries and $72.6 \%$ experienced caries. ${ }^{5}$

Caries is a multifactorial symptom that could occur

How to Cite: Rafitha H, Bungsu P, Djuwita R, Gayatri D, Ayub FA. Overweight and obesity status with dental caries among children aged 7-12 years old in Badung District, Bali 2018. Kesmas: National Public Health Journal. 2019; 14 (2): 65-69. (doi:10.21109/kesmas.v14i2.3008) through interaction of certain factors, including cariogenic microorganisms, oral hygiene behaviors, eating habits, dietary carbohydrates, socioeconomic conditions, and other factors. ${ }^{6}$ Caries is caused by Streptococcus mutans, which inhabits the surface of teeth plaque. ${ }^{7}$ Streptococcus mutans produces acid which would generate organic acids in the $\mathrm{pH}$ range of 3.8 to 4.8 when exposed to dietary carbohydrates. This acidity could cause demineralization on the tooth surface, which might result in cavities in the enamel layer. If left untreated, this condition often becomes detrimental to the deep tooth layers, causing severe pain, difficulty in chewing food, and production of digestive disturbances, which might lead to malnutrition. ${ }^{7-9}$ Another factor is the high consumption of carbohydrate, which would increase the body weight and the prevalence of dental caries. ${ }^{10}$

Obesity is the result of chronic inconsistency between

Correspondence*: Putri Bungsu, Epidemiology Department, Faculty of Public Health, Universitas Indonesia, A Building 1st Floor, Kampus Baru UI Depok, Indonesia, Phone: +6282122044786,E-mail: putri.bungsu10@ui.ac.id

Received : February $14^{\text {th }} 2019$

Revised : June 26th 2019

Accepted : July $15^{\text {th }} 2019$ 
food intake and energy use. ${ }^{11}$ The majority of overweight children follow a lifestyle of high-fat and high-carbohydrate food intake but sedentary lifestyle. ${ }^{11}$ A distinct relationship exists between high sugar consumption, which is an important risk factor for obesity, and dental caries. ${ }^{12}$ Obesity is a chronic disease that is considered a global epidemic. The prevalence of obesity worldwide is a major concern because of its long-term potential impact on morbidity, mortality, and health care costs. ${ }^{13}$ Obese children are more likely to be overweight in their adulthood and face increased risks of morbidity and mortality. ${ }^{13}$

According to the World Health Organization (WHO), obesity has reached epidemic proportions globally, with more than one billion adults being overweight and at least 300 million of them being clinically obese; obesity is also a major contributor to the global burden of chronic diseases and morbidity. ${ }^{14}$ Although obesity only occurs in high-income countries, the WHO reports that overweight and obesity are currently dramatically increasing in low- and middle-income countries. ${ }^{15}$ The global prevalence of obesity in children has increased substantially in recent years. ${ }^{13}$ In the United Kingdom, the prevalence of overweightness and obesity in adolescents (11 - 15 years) increased from 28\% (male) and $30 \%$ (female) in 1995 to $36 \%$ for both male and female in 2013.13

Indonesian National Health Survey of 2013 stated that Indonesia faces the problem of overweightness and obesity in children aged 5 - 12 years, with a total prevalence of $18.8 \%$ (overweightness: $10.8 \%$; obesity: $8 \%$ ). ${ }^{4}$ A total of 15 provinces, including Bali Province, present higher rates of overweightness and obesity among children aged 5 - 12 years compared to the national average. 4 Bali Province had a prevalence rate of $21.4 \%$, with $12.6 \%$ accounting for overweightness and $8.8 \%$ representing obesity. ${ }^{16}$ In addition, $39.8 \%$ of people have dental caries, and $65.6 \%$ have experienced dental caries in Bali Province. ${ }^{5}$ Badung District is one of three districts in Bali Province with high rates of overweightness and obesity, exceeding the national average. ${ }^{16}$ Badung District has a total prevalence rate of $30.1 \%$ for overweightness and obesity, with $14.9 \%$ accounting for overweightness and $15.2 \%$ accounting for obesity. Badung District also features a dental caries prevalence approaching the national average, e.g., $43 \%$ of people have dental caries, and $63.7 \%$ had experienced dental caries. ${ }^{16}$ This study aimed to assess child overweightness and obesity in relation to dental caries in Badung District, Bali Province.

\section{Method}

This quantitative study was employing a cross-sectional study approach, and it used primary data by dental caries examinations, measuring body weight, height, and interviewing the respondents' mothers in May 2018. This study evaluated the causal relationship between obesity status and dental caries. The independent variable was obesity status, which was divided into the exposed group if the respondents' weight-for-height Z-scores were $\geq+2$ standard deviation (SD) (overweight or obese) and nonexposed group if the Z-scores were $-2 \mathrm{SD}$ until +2 SD (normal). The outcome was dental carries among children 7 - 12 years. This study also measured other variables, such as maternal education, maternal employment, family income, fast food intake, snack and sweet drinking intake, and oral hygiene, which were evaluated as potential confounders. The study population included all primary school children in Badung District, Bali Province and their mothers, and the study sample comprised of all elementary school students grade 1 - 5 from three randomly selected public elementary schools. The selection of three public primary schools was carried out through simple random sampling from a list of 255 public elementary schools in Badung District. The sample size was calculated by the two-proportion formula and by 344 samples. Missing data were considered in this study. The study sample was then added to the 426 children who had met the study inclusion criteria, including parent approval, school attendance during the study data collection, returning of the questionnaire, and willingness to undergo anthropometric measurement at the time data collected. Data collection was carried out by using digital scales and microtoize height gages. Dental examinations were performed by using oral diagnostic tools, which were sterilized by immersing the appliance in $5.25 \%$ sodium hypochlorite solution with 1:10 dilution. ${ }^{17}$ A questionnaire related to oral hygiene behavior was adapted from the previous study questionnaire of Winnier JJ et al., ${ }^{18}$ e.g., Oral Hygiene Maintenance in Children-A survey of Parental Awareness. Furthermore, food frequency questionnaires were adapted from the work of Olivia Teresa Boniface, ${ }^{19}$ concerning the validation of a short food frequency questionnaire that ranks pacific Islanders living in South Auckland, New Zealand by sugar intake. The questionnaire was tested on 36 students from 02 Kerobokan Kelod Elementary School. The data retrieval procedure started with the distribution of consent sheets accompanied by a questionnaire for mothers of students through students who came to school assisted by the teacher; the students were instructed to return the questionnaire the next day or after a maximum of two days. After the approval sheet and questionnaire were returned to the researcher, the study was continued by examining the teeth, weight, and height of the children. The students were excluded from the study in case of failure to return the approval sheet and questionnaire. The examination 
in this study was carried out by the researcher and a research assistant who is a graduate student of the Faculty of Public Health Universitas Indonesia. The research assistant was assigned to document or record the obtained data following the instructions of the researcher. The data were analyzed by using chi-square as crude analysis and logistic regression as multivariate analysis. This study was approved by the institutional review board of the Faculty of Public Health Universitas Indonesia with research ethics number 470/UN2.F10/PM.00.02/2018.

\section{Results}

Table 1 illustrates that the proportion of overweight and obese children $(51.2 \%)$ is slightly higher than children with normal nutritional status $(48.8 \%)$. The table also shows that of 426 respondents, 229 children $(53.8 \%)$ have a high number of dental caries with a de-

Table 1. Distribution of Respondents by Characteristics of Mother and Child, Diet, Oral Hygiene Behavior, and Childhood Overweightness and Obesity Status

\begin{tabular}{llcc}
\hline Variable & Category & n & $\%$ \\
\hline Status of obesity & Overweight \& obesity (Z-score > 1 SD) & 218 & 51.2 \\
& Normal (Z-score -2 SD to 1 SD) & 208 & 48.8 \\
Dental caries status & Height (DMF-T > 3) & 229 & 53.8 \\
& Low (DMF-T $\leq 3)$ & 197 & 46.2 \\
\hline
\end{tabular}

Notes: DMF-T : Decay-missing-filled teeth cay-missing-filled teeth (DMF-T) score $>3$. The remaining 197 children $(46.2 \%)$ presented a low dental caries status with a DMF-T score $\leq 3$.

Table 2 demonstrates that overweight and obese children account for a higher proportion of dental caries experience $(60.6 \%)$ compared with normal children $(52.0 \%)$. Moreover, a statistically significant relationship was observed between overweightness and obesity and the incidence of dental caries (odds ratio (OR): 1.72; 95\% confidence interval (CI): 1,17-2,52). Therefore, overweight and obese children have 1.72 odds of experiencing dental caries compared to normal-weight children. Table 2 also shows three other variables forming a relationship with dental caries; such as fast food diet (OR: 1.50; 95\% CI: 1,02-2,20), sugary snack and beverage diet (OR: 1.65; 95\% CI: 1.12-2.42), and oral hygiene habit (OR 1.60; 95\% CI: 1.086-2.34).

Five variables had a p-value $<0.25$ : obesity status, fast food eating pattern, snack and sweet drink diet, oral hygiene behavior, and family income (Table 3). These five variables were included in the multivariate analysis. The confounding assessment in this study was run in stratification analysis by comparing the OR values to the exposure variables before and after the covariate was removed from the model (Table 4).

Table 4 shows that all candidate variables that are candidates for the multivariate analysis are confounding

Table 2. Relationship between Characteristics of Mother and Child, Diet, Oral Hygiene Behavior, and Status of Obesity

\begin{tabular}{|c|c|c|c|c|c|}
\hline \multirow{2}{*}{ Variable } & \multirow{2}{*}{ Category } & \multicolumn{2}{|c|}{ Dental Caries Status } & \multirow{2}{*}{ OR } & \multirow{2}{*}{ p-Value } \\
\hline & & High* & Low ${ }^{*}$ & & \\
\hline \multirow[t]{2}{*}{ Status of obesity } & Obesity & $126(60.6)$ & $82(39.4)$ & 1.72 & $0.006 *$ \\
\hline & Normal & $103(47.3)$ & $115(52.8)$ & $(1.17-2.52)$ & \\
\hline \multirow[t]{2}{*}{ Mother's education } & Under senior high school & $90(54.9)$ & $74(45.1)$ & 1.08 & 0.713 \\
\hline & Senior high school and above & $139(53.0)$ & $123(47.0)$ & $(0.73-1.59)$ & \\
\hline \multirow[t]{2}{*}{ Mother's employment } & Employed & $158(55.4)$ & $127(44.6)$ & 1.23 & 0.322 \\
\hline & Unemployed & $71(50.4)$ & $70(49.7)$ & $(0.82-1.84)$ & \\
\hline \multirow[t]{2}{*}{ Family income } & Under minimum wage & $54(62.1)$ & $33(37.9)$ & 1.53 & 0.081 \\
\hline & RMW and above & $175(51.6)$ & $164(48.4)$ & $(0.95-2.49)$ & \\
\hline \multirow[t]{2}{*}{ Child's sex } & Male & $116(54,5)$ & $105(47.5)$ & 0.84 & 0.380 \\
\hline & Female & $113(55.1)$ & $92(44.9)$ & $(0.57-1.24)$ & \\
\hline \multirow[t]{2}{*}{ Fast food (carbohydrate) diet } & High & $123(58.9)$ & $86(41.2)$ & 1.50 & $0.038 * *$ \\
\hline & Low & $106(48.9)$ & $111(51.2)$ & $(1.02-2.20)$ & \\
\hline \multirow[t]{2}{*}{ Snack / sweet drinking diet } & High & $126(60.0)$ & $84(40.0)$ & 1.65 & $0.011 * *$ \\
\hline & Low & $103(47.7)$ & $113(52.3)$ & $(1.12-2.42)$ & \\
\hline \multirow[t]{2}{*}{ Oral hygiene } & Not good & $138(59.0)$ & $96(41.0)$ & 1.60 & $0.017 * *$ \\
\hline & Good & $91(47.4)$ & $101(52.6)$ & $(1.09-2.34)$ & \\
\hline
\end{tabular}

Notes: *n(\%), **p-value < 0.05, OR = Odd Ratio, RMW = Regional Minimum Wage

Table 3. Variables that Meet Criteria for Multivariate Analysis

\begin{tabular}{lccc}
\hline Variable & p-Value & OR & 95\% CI \\
\hline Family income & 0.081 & 1.53 & $(0.95-2.50)$ \\
Fast food diet & 0.038 & 1.50 & $(1.02-2.20)$ \\
Sweet snack pattern & 0.011 & 1.65 & $(1.12-2.42)$ \\
Oral hygiene behavior & 0.017 & 1.60 & $(1.09-2.34)$ \\
Status of obesity & 0.006 & 1.72 & $(1.17-2.52)$ \\
\hline
\end{tabular}

Notes: $\mathrm{CI}=$ Confidence Interval, OR = Odds Ratio
Table 4. Conclusion of Confounding Test Results for Multivariate Candidate Variables

\begin{tabular}{lcccc}
\hline Variable & COR & AOR & Confounding & Interaction \\
\hline Status of obesity & 1.72 & & & \\
Fast food diet & & 1.74 & + & - \\
Sweet snack pattern & & 1.70 & + & - \\
Oral hygiene behavior & & 1.66 & + & - \\
Family income & 1.83 & + & - \\
\hline
\end{tabular}

Notes: $\mathrm{COR}=$ Crude Odds Ratio, $\mathrm{AOR}=$ Adjusted Odds Ratio 
Table 5. Final Model of Multivariate

\begin{tabular}{lcccc}
\hline Variable & Wald & p-Value & OR & 95\% CI \\
\hline Obesity & 9.23 & 0.003 & 1.83 & $1.23-2.72$ \\
Family income & 5.75 & 0.034 & 1.72 & $1.04-2.84$ \\
Sweet snack / drink diet & 6.78 & 0.009 & 1.69 & $1.14-2.50$ \\
Oral hygiene & 6.69 & 0,010 & 1.68 & $1.13-2.50$ \\
\hline
\end{tabular}

Notes: $\mathrm{CI}=$ Confidence Interval, $\mathrm{OR}=$ Odd Ratio

variables. Thus, the mentioned five variables were continually used in the multivariate analysis. The final stage of the multivariate analysis involved the calculation for the logistic regression tests carried out using backward method.

As shown in Table 5, in the final multivariate results, four variables, including obesity status, family income, snack and sweet drink diet, and oral hygiene behavior, presented a significant relationship with dental caries. Therefore, the incidence of obesity bears a relationship with the incidence of dental caries after controlling for the variables including dietary snack and sweet drinks, family income, and oral hygiene behavior. Obese children aged 7-12 years have an almost twofold risk of experiencing dental caries compared with children who are not obese (OR: 1.83; 95\% CI: 1.23-2.72). While, snack diet and sweet drinks, family income, and oral hygiene influenced the relationship of overweightness and obesity with dental caries incidence among children aged 7-12 years in Badung District in 2018.

\section{Discussion}

Obesity among children has become the focus of public health throughout the world. ${ }^{14}$ The majority of overweight children follow a lifestyle of high-fat and high-carbohydrate food intake and sedentary lifestyle. ${ }^{11}$ A distinct relationship exists between high sugar consumption, which is a significant risk factor for obesity, and dental caries. ${ }^{12}$ This study compared caries prevalence using the DMF-T index with normal nutritional status and obesity groups, in which the obesity category included the overweight status (Z-score $>1 \mathrm{SD}$ ). This study suggests that obesity plays an important role in the incidence of dental caries in children aged 7-12 years after controlling for variables such as family income, oral hygiene behavior, snack diet, and sweet drinks.

This study is similar to the study by Hayden C et al.,20 who stated the association between obesity and dental caries with a p-value of 0.049. ${ }^{20}$ Moreover, Bhayat et al., 10 argued the strong relationship between obesity and dental caries. Their study was conducted on normal samples versus obesity and overweightness samples, obtaining an OR value of 1.77 and p-value of 0.016 ; thus, children with obesity would be at risk of 1.77 times experiencing dental caries ${ }^{10}$ Bafti et al., ${ }^{11}$ also suggested the significant relationship between body mass index (normal vs overweight) and dental caries with a p-value of 0.0001 (OR: 1.449).

Tooth decay or caries and obesity are both considered multifactorial entities with genetic predisposition and environmental conditions. Most of the factors involved in obesity and tooth decay result from the changes in lifestyle and environmental factors. This alteration in physical activity and nutrition services occurs at home and school environment. ${ }^{11}$ When children frequently watch TV for long durations, they tend to snack more than the normal circumstances, especially on foods containing high amounts of fat and/or sugar. This condition increases the overall calorie intake, which could lead to obesity, and raises the risk of developing tooth decay due to prolonged contact time between food and the teeth surface. ${ }^{21}$ In addition, the simultaneous intake of sugary foods might result in weight gain and increase the risk of caries. ${ }^{10}$ A relationship exists between obesity and the incidence of dental caries in children aged 7-12 years in Badung District. Obese children would face doubled risk of dental caries compared with children who are not obese. This result suggests that if childhood obesity could be prevented among children, then they are less likely to experience dental caries. Therefore, strengthening the existing health education programs in schools, including those on healthy food or snack components, and improving the efficiency of physical activities for preventing obesity could be a short-term strategy to protect school-age kids from childhood obesity and dental caries.

This study discovered that covariate variables, such as family income, eating habits and sweet drinks, and oral hygiene behavior, influence the strength of the relationship between overweightness and obesity among children and dental caries. Family income can affect dental caries, as proven by a previous study reporting that family income was significantly related to the low prevalence of dental caries in children (OR: 1.22; 95\% CI: 1.01-1.50).22 Furthermore, snacks or sweet drinks were found to be significantly associated with dental caries in children (OR: 1.686; 95\% CI : $1.03-1.50) .{ }^{23} \mathrm{~A}$ previous study showed a similar result, revealing a significant relationship between the frequency of sugar intake and dental caries. Dietary habits play an important role in the development of dental caries, mainly because of high rates of carbohydrate fermentation. ${ }^{24}$ Oral hygiene behavior can also influence the relationship between obesity and dental caries. This study revealed a significant relationship between dental hygiene practices and caries (OR: 1.683; 95\% CI: 1.13-2.50). Similar results were obtained in the previous study of $\mathrm{Wu} \mathrm{L}$ et $a l .{ }^{12}$ The findings indicate that in relation to the oral hygiene behavior, the mouth condition would be protected from bacteria. ${ }^{25}$ 


\section{Conclusion}

A relationship exists between obesity in children and the incidence of dental caries after controlling other variable in children aged 7-12 years in Badung District,while obese children show two-fold the risk of dental caries compared to children who are not obese.

\section{References}

1. So M, Ellenikiotis YA, Husby HM, Paz CL, Seymour B, Sokal-Gutierrez K. Early childhood dental caries, mouth pain, and malnutrition in the ecuadorian amazon region. International Journal Environmental Research Public Health. 2017; 14 (550): 1-12.

2. Dye B, Thornton-Evans G, Li X, Iafolla TJ. Dental caries and sealant prevalence in children and adolescents in the United States, 2011 2012. NCHS Data Brief. 2015; (191): 1-8.

3. World Health Organization. Expert consultation on public health intervention against early childhood caries. 2016: 1-28.

4. Badan Penelitian dan Pengembangan Kesehatan Kementerian Kesehatan RI. Riset Kesehatan Dasar (RISKESDAS) 2013. Lap Nas 2013. 2013: $1-384$.

5. Kementerian Kesehatan Republik Indonesia. Profil pelayanan kesehatan gigi dan mulut; 2014.

6. Duangthip D, Gao SS, Lo ECM, Chu CH. Early childhood caries among 5- to 6-year-old children in Southeast Asia. International Dental Journal. 2017; 67 (2): 98-106.

7. California Dental Association. Early childhood caries. 1201 K Street, Sacramento. 2017: 1-2.

8. Wong A, Subar PE, Young DA. Dental caries: An update on dental trends and therapy. Advances in Pediatrics. 2017; 64 (1): 307-30.

9. Mishu M, Hobdell M, Khan M, Hubbard R, Sabbah W, Wael. Relationship between untreated dental caries and weight and height of 6-to 12-year-old primary school children in Bangladesh. International Journal of Dentistry. 2013: 10-14.

10. Bhayat A, Ahmad MS, Fadel HT. Association between body mass index, diet and dental caries in grade 6 boys in Medina, Saudi Arabia. East Mediterranean Health Journal. 2016; 22 (9): 687-93.

11. Bafti LS, Hashemipour MA, Poureslami H, Hoseinian Z. Relationship between body mass index and tooth decay in a population of 3 - 6-yearold children in Iran. International Journal of Dentistry. 2015.

12. Wu L, Chang R, Mu Y, Deng X, Wu F, Zhang S, et al. Association between obesity and dental caries in chinese children. Caries Research.
2013; 47 (2): 171-6.

13. Hall-Scullin EP, Whitehead H, Rushton H, Milsom K, Tickle M. A longitudinal study of the relationship between dental caries and obesity in late childhood and adolescence. Journal Public Health Dentistry. 2017; (4).

14. World Health Organization. Regional Office for South-East Asia. Overweight and obesity fact sheet. 2011: 1-2.

15. Krishnamurthy K, Bangar BR, Raja A, Gujaral GS, Randive SB, Vaishnav KP. Body mass index and its impact on dental caries. 2017; 10 (4): 810-4.

16. Riskesdas Provinsi Bali. Riset Kesehatan Dasar 2013 Provinsi Bali. Kementerian Kesehatan Republik Indonesia; 2013.

17. CDC. Infection control guideline for disinfection and sterilization in healthcare facilities. Edits and Changes February 2017; 2017 [cited 2019 Jul 3]. Available from: https://www.cdc.gov/infectioncontrol/guidelines/disinfection/updates.html\#anchor_1554393470.

18. Winnier JJ, Parmar A, Mehta S, Bambal K, Bhatia R. Oral hygiene maintenance in children: a survey of parental awareness. International Journal Oral Health Medical Research. 2015; 6 (3).

19. Boniface OT. Validation of a short food frequency questionnaire which ranks individuals by sugar intakes in pacific islanders in South Auckland, New Zealand. New Zealand; 2013.

20. Hayden C, Jo B, Chambers S, et al. Dental caries is related to obesity in children but the relationship is moderated by socio-economic strata and child age. Journal of Evidence Based Dental Practice. 2018; 14 (1): 1618.

21. Alswat K, Mohamed WS, Wahab MA, Aboelil AA. The association between body mass index and dental caries: cross-sectional study. Journal of Clinical Medicine Research. 2016; 8 (2): 147-52.

22. Costa LR, Daher A, Queiroz MG. Early childhood caries and body mass index in young children from low income families. BioMed Central Oral Health. 2013; 10: 867-78.

23. Chen KJ, Gao SS, Duangthip D, et al. Dental caries status and its associated factors among 5 -year-old Hong Kong children : a cross-sectional study. 2017: 1-8.

24. Anil S, Anand PS. Early childhood caries: prevalence, risk factors, and prevention. Frontiers in Pediatrics. 2017; 5 (157): 1-7.

25. Masyarakat BK, Alhamda S, Gigi JK, Padang PK. Status kebersihan gigi dan mulut dengan status karies gigi (kajian pada murid kelompok umur 12 tahun di Sekolah Dasar Negeri Kota Bukittinggi). Jurnal Berita Kedokteran Masyarakat. 2011; 27 (2): 108-15. 